\title{
Kinneretia asaccharophila gen. nov., sp. nov., isolated from a freshwater lake, a member of the Rubrivivax branch of the family Comamonadaceae
}

Correspondence

Jorge Lalucat

jlalucat@uib.es

\author{
Margarita Gomila, ${ }^{1,2}$ Jarone Pinhassi, ${ }^{3}$ Enevold Falsen, ${ }^{2}$ \\ Edward R. B. Moore ${ }^{2,4}$ and Jorge Lalucat ${ }^{1}$
}

\footnotetext{
${ }^{1}$ Microbiologia, Departament de Biologia, Universitat de les Illes Balears, and Institut Mediterrani d'Estudis Avançats (CSIC-UIB), 07122 Palma de Mallorca, Illes Balears, Spain

${ }^{2}$ CCUG - Culture Collection University of Göteborg, University of Göteborg, SE-413 46 Göteborg, Sweden

${ }^{3}$ Marine Microbiology, Department of Pure and Applied Natural Sciences, University of Kalmar, SE-391 82 Kalmar, Sweden

${ }^{4}$ Sahlgrenska University Hospital, University of Göteborg, SE-413 46 Göteborg, Sweden
}

\begin{abstract}
A strictly aerobic, Gram-negative bacterium, strain $\mathrm{KIN}_{19} 2^{\top}$, isolated from fresh water from Lake Kinneret, Israel, was examined using a polyphasic approach to characterize and clarify its phylogenetic and taxonomic position. Sequences of the 16S rRNA and gyrB genes and ITS1 revealed close relationships to species of the genera Pelomonas, Mitsuaria and Roseateles, in the Rubrivivax branch of the family Comamonadaceae of the Betaproteobacteria. Physiological and biochemical tests, cellular fatty acid analysis and DNA-DNA hybridizations indicated that this strain should be assigned to a new genus and species in the Rubrivivax phylogenetic branch, for which the name Kinneretia asaccharophila gen. nov., sp. nov., is proposed. The type strain of Kinneretia asaccharophila is strain $\mathrm{KIN}_{192}{ }^{\top}$ (=CCUG $53117^{\top}=$ CECT $7319^{\top}$ ).
\end{abstract}

Strain $\mathrm{KIN}_{192}{ }^{\mathrm{T}}\left(=\right.$ CCUG $\left.53117^{\mathrm{T}}\right)$ was isolated from surface waters of the freshwater Lake Kinneret, Israel, by Pinhassi \& Berman (2003). This strain was one of the dominant colony-forming bacteria in an enrichment culture experiment, with additions of glucose, ammonium and phosphate, carried out on 11 September 2000. Strain KIN192 ${ }^{\mathrm{T}}$ accounted for approximately $42 \%$ of colonyforming units (total 54000 c.f.u. $\mathrm{ml}^{-1}$ ), suggesting that it is an organism that prefers eutrophic growth conditions. At the time of the experiment, with a lake water temperature of $29{ }^{\circ} \mathrm{C}$, close to the annual maximum recorded for the lake, bacterial growth in the lake was markedly limited by low levels of phosphorus. Isolate $\mathrm{KIN} 192^{\mathrm{T}}$ was provisionally ascribed to the Pelomonas-Roseateles-Mitsuaria phylogenetic branch, based on $16 \mathrm{~S}$ rRNA gene sequence analysis. The relative branching order of most species within the group is difficult to determine because of the limited

The GenBank/EMBL/DDBJ accession numbers for the sequences determined in this study are AY136099 (16S rRNA gene sequence of strain KIN192 ${ }^{\top}$ ), FM945414-FM945427 (gyrB sequences) and FM945412 and FM945413 (ITS1 sequences).

An electron micrograph of a cell of strain $\mathrm{KIN1}^{\mathrm{N}} 2^{\top}$, ITS1- and gyrBbased dendrograms, ITS1 and gyrB sequence similarities and detailed Biolog and DNA-DNA hybridization results are available as supplementary material with the online version of this paper. number of variable positions available for estimating the phylogenetic distances between strains (Spring, 2006). However, molecular techniques have recently enabled better discrimination of the different species in the Rubrivivax line of descent (Gomila et al., 2007, 2008). Comprehensive molecular analyses together with phenotypic and biochemical characterizations have enabled the elucidation of the taxonomic affiliations for organisms within this group (Amakata et al., 2005; Gomila et al., 2007, 2008; Kalmbach et al., 1999; Suyama et al., 1999; Xie \& Yokota, 2005). In the present study, strain $\mathrm{KIN}_{192}{ }^{\mathrm{T}}$ is concluded to represent a new genus and species.

Strains used in this study included the type strains of all species with validly published names belonging to the closely related genera Aquabacterium, Mitsuaria, Pelomonas and Roseateles: Aquabacterium citratiphilum CCUG 53899 ${ }^{\mathrm{T}}$, Aquabacterium commune CCUG $48318^{\mathrm{T}}$, Aquabacterium parvum CCUG $48317^{\mathrm{T}}$, Mitsuaria chitosanotabida IAM $14711^{\mathrm{T}}$, Pelomonas aquatica CCUG $52575^{\mathrm{T}}$, Pelomonas puraquae CCUG $52769^{\mathrm{T}}$, Pelomonas saccharophila CCUG $32988^{\mathrm{T}}$, Roseateles aquatilis CCUG $48205^{\mathrm{T}}$, Roseateles depolymerans CCUG $52219^{\mathrm{T}}$, and Roseateles terrae CCUG $52222^{\mathrm{T}}\left(=\mathrm{MC1} 2^{\mathrm{T}}\right.$, isolated by Suyama et al., 1998). All strains used in this study were cultivated on Reasoner's R2A medium (Reasoner \& Geldreich, 1985) and incubated 
for 3-4 days at $30{ }^{\circ} \mathrm{C}$ prior to analyses, if not otherwise stated.

Cell size, morphology and flagella insertion were determined by transmission electron microscopy of cells from the exponential growth phase in R2A broth. A Hitachi model H600 electron microscope was used at $75 \mathrm{kV}$. Negative stains of cells were prepared with phosphotungstic acid [1\%(w/v), pH 7.0], as described by Lalucat (1988). The following phenotypic tests were used: API 20NE (identification system for Gram-negative, non-enterobacterial rods), API 50CH, API ZYM enzyme and assimilation tests, according to the instructions of the manufacturer (bioMérieux). Biolog analyses were also carried out, essentially according to the instructions of the manufacturer, as described previously (Gomila et al., 2007, 2008). Conventional phenotypic tests were done according to the methods of Cowan (1974). Growth rates in R2A medium were determined at different temperatures $(4,10,20,30,37$ and $45^{\circ} \mathrm{C}$ ).

Colonies of strain KIN $192^{\mathrm{T}}$ were small, approximately $2-$ $3 \mathrm{~mm}$ in width, cream-coloured and translucent with irregular and undulate margins. Cells were Gram-negative, rod-shaped (approx. $2 \mu \mathrm{m}$ long) and motile by means of a single polar flagellum (Supplementary Fig. S1, available in IJSEM Online). Differential phenotypic characteristics and substrates assimilated or utilized as sole carbon and energy sources are indicated in Table 1. Strain KIN192 ${ }^{\mathrm{T}}$ grew well between 20 and $37^{\circ} \mathrm{C}$, but was not able to grow at 4,10 or $45^{\circ} \mathrm{C}$. Strain $\mathrm{KIN} 192^{\mathrm{T}}$ exhibited a phenotypic profile different from that of any of the other strains studied. Phenylacetic acid assimilation, $\beta$-glucosidase activity and nitrate reduction are characteristic and differential for strain $\mathrm{KIN} 192^{\mathrm{T}}$. It was not able to assimilate any sugar that was tested, allowing its differentiation from the species of the genus Pelomonas and from the species of the closely related genera Mitsuaria and Roseateles. Differential phenotypic characteristics from species in closely related genera are the inability of strain $\mathrm{KIN}_{192}{ }^{\mathrm{T}}$ to grow chemolithoautotrophically, to grow as a diazotroph or to produce photosynthetic pigments. It shows positive reactions for a few hydrolytic enzymes: alkaline phosphatase, esterase lipase (C8), esterase (C4) and leucyl arylamidase. The positive reaction for alkaline phosphatase observed for strain $\mathrm{KIN} 192^{\mathrm{T}}$ might be expected, given the phosphorus limitation in the ecosystem from which the strain was isolated. Biolog substrates utilized as electron donors are indicated in Supplementary Table S1.

Genomic DNA was prepared, 16S rRNA genes were amplified by PCR and PCR products were sequenced as described previously (Gomila et al., 2005). Sequence data were edited manually and primer sequences were removed. Gene sequences were aligned with reference sequences of the closest relatives, retrieved using the BLAST analysis tool and the NCBI nucleotide sequence database (Altschul et al., 1990). A hierarchical method for multiple alignments, implemented in the CLUSTAL_X program (Thompson et al.,
Table 1. Differential phenotypic characteristics between strain KIN $192^{\top}$ and species of the closely related genera Mitsuaria, Pelomonas and Roseateles

Strains: 1, KIN192 ${ }^{\mathrm{T}}$ (Kinneretia asaccharophila gen. nov., sp. nov.); 2, P. saccharophila CCUG $32988^{\mathrm{T}}$; 3, P. aquatica CCUG $52575^{\mathrm{T}} ; 4, P$. puraquae CCUG $52769^{\mathrm{T}}$; 5, M. chitosanotabida IAM $14711^{\mathrm{T}} ; 6, R$. depolymerans CCUG 52219 ${ }^{\mathrm{T}}$; 7 , R. terrae CCUG $52222^{\mathrm{T}}$; 8, R. aquatilis CCUG $48205^{\mathrm{T}}$. + , Positive; -, negative; w, weak; v, variable; ND, not determined. Data were obtained in this study unless indicated. All strains exhibit polar flagella (flagellation data for $R$. depolymerans CCUG $52219^{\mathrm{T}}$ from Suyama et al., 1999) and are oxidase-positive.

\begin{tabular}{|c|c|c|c|c|c|c|c|c|}
\hline Characteristic & 1 & 2 & 3 & 4 & 5 & 6 & 7 & 8 \\
\hline Flagella & 1 & 1 & 1 & 1 & 1 & Several & 1 & 1 \\
\hline \multicolumn{9}{|l|}{ Growth at: } \\
\hline $10{ }^{\circ} \mathrm{C}$ & - & - & - & + & + & + & $\mathrm{w}$ & - \\
\hline $37{ }^{\circ} \mathrm{C}$ & + & - & + & + & + & + & + & - \\
\hline Pigmentation & - & - & - & - & - & $+^{*}$ & $+^{*}$ & - \\
\hline $\begin{array}{l}\text { Autotrophic growth } \\
\text { with } \mathrm{H}_{2}\end{array}$ & ND & + & - & + & - & - & - & - \\
\hline \multicolumn{9}{|l|}{$\begin{array}{l}\text { Amplification product } \\
\text { for: }\end{array}$} \\
\hline$c b b L$ & - & + & - & + & - & - & - & - \\
\hline hox & - & ND & - & + & - & - & ND & $\mathrm{ND}$ \\
\hline nifH & - & + & - & + & - & + & + & - \\
\hline puf & - & - & - & - & - & + & + & - \\
\hline Catalase & - & - & - & - & - & + & + & - \\
\hline Nitrate reduction & + & + & + & $\mathrm{V}$ & + & - & - & - \\
\hline Urease & - & - & - & - & - & + & - & - \\
\hline$\beta$-Glucosidase & - & + & + & + & + & + & + & - \\
\hline Gelatin hydrolysis & + & - & - & + & + & + & + & + \\
\hline$\beta$-Galactosidase & - & + & - & + & + & + & + & - \\
\hline \multicolumn{9}{|l|}{ Assimilation of: } \\
\hline D-Glucose & - & + & - & + & + & + & + & + \\
\hline L-Arabinose & - & + & - & + & - & + & + & - \\
\hline D-Mannose & - & $\mathrm{V}$ & - & - & - & + & + & - \\
\hline D-Mannitol & - & - & - & - & - & + & + & - \\
\hline $\begin{array}{l}N- \\
\text { Acetylglucosamine }\end{array}$ & - & + & - & - & - & - & - & - \\
\hline Maltose & - & + & - & + & + & + & + & + \\
\hline Gluconate & + & + & - & - & + & + & + & + \\
\hline Capric acid & - & - & - & - & + & $\mathrm{w}$ & + & - \\
\hline Adipic acid & $\mathrm{w}$ & - & - & - & - & $\mathrm{w}$ & - & - \\
\hline Malic acid & - & $\mathrm{V}$ & - & + & + & $\mathrm{w}$ & $\mathrm{w}$ & + \\
\hline Citrate & - & - & - & $\mathrm{W}$ & + & $\mathrm{W}$ & - & - \\
\hline Phenylacetic acid & + & - & - & - & w & - & - & - \\
\hline $\begin{array}{l}\text { DNA G + C content } \\
(\mathrm{mol} \%)\end{array}$ & 69.3 & 70.9 & 72.7 & 70.0 & 71.3 & 68.0 & 68.0 & 70.1 \\
\hline
\end{tabular}

${ }^{\star}$ Pigmented under some conditions, according to Suyama et al. (1999).

1997), was used to create sequence alignments. Automatically aligned sequences were checked manually and all positions of ambiguous identity were removed for subsequent analyses. Sequence similarities and evolutionary distances were calculated using programs implemented in PHYLIP version 
3.5c (Felsenstein, 1989). The 16S rRNA gene sequence of strain $\mathrm{KIN}_{192}{ }^{\mathrm{T}}$ exhibited similarities between 98.0 and $98.9 \%$ with sequences of the type strains of described species from the genera Mitsuaria, Pelomonas and Roseateles. Similarities were distinctly lower, $95.6-96.0 \%$, between the 16S rRNA gene sequence of KIN192 ${ }^{\mathrm{T}}$ and those of species of the closely related genera Aquabacterium and Rubrivivax (Fig. 1; Supplementary Table S2). The 16S rRNA gene phylogenetic tree clusters strain $\mathrm{KIN}_{192}{ }^{\mathrm{T}}$ within the Pelomonas and Mitsuaria phylogenetic branch, although the position of the Mitsuaria chitosanotabida branch exhibited a relatively low bootstrap confidence (539/1000 replications). Although comparative 16S rRNA gene sequence analysis is able to place strain $\mathrm{KIN} 192^{\mathrm{T}}$ within the Rubrivivax lineage, closely related to the species of Pelomonas and Mitsuaria, it is not able to determine with confidence whether strain $\mathrm{KIN} 192^{\mathrm{T}}$ represents a novel species of Pelomonas or of Mitsuaria or a novel species of a new genus.

The sequence of the spacer region between the $16 \mathrm{~S}$ and $23 \mathrm{~S}$ rRNA genes, ITS1, of strain KIN192 ${ }^{\mathrm{T}}$ was analysed as a marker for higher-resolution differentiation than is possible by comparative $16 \mathrm{~S}$ rRNA gene sequence analyses. Additionally, ITS1 sequence analyses have been shown to correlate well with genomic DNA-DNA hybridization results in delineating bacterial genotypic species or genomovars (Guasp et al., 2000). ITS1 regions were amplified and sequenced, using the methods described by

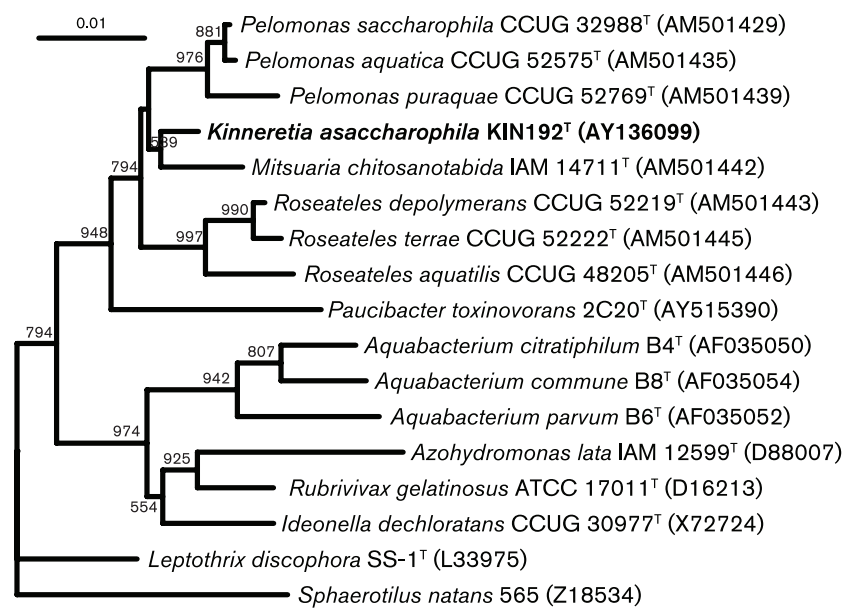

Fig. 1. Phylogenetic tree, based on $16 \mathrm{~S}$ rRNA gene sequence comparisons over 1341 aligned bases, showing estimated relationships between strain KIN192 ${ }^{\top}$ (Kinneretia asaccharophila gen. nov., sp. nov.) and the type strains of species of the closely related genera Mitsuaria, Pelomonas and Roseateles in the Betaproteobacteria. The tree was constructed using the neighbour-joining method, following distance analysis calculated by the method of Jukes \& Cantor (1969). The topology of the tree was visualized by means of the TreeView program (Page, 1996). Bootstrap values greater than 500 , based on 1000 replications, are indicated at branching nodes. Accession numbers are given in parentheses. Bar, 0.01 nucleotide substitutions per site.
Gomila et al. (2007), and the sequence data were handled as described for the 16S rRNA gene sequence. ITS1 sequences of $\mathrm{KIN}_{192}{ }^{\mathrm{T}}$ and reference organisms for which ITS1 could be amplified by PCR were aligned and pairwise similarities (Supplementary Table S2) and cluster analyses (Supplementary Fig. S2) were calculated. While the ITS1 sequence similarities did not provide definitive evidence, in the case of the genera of the Rubrivivax phylogenetic lineage, the ITS1 sequence similarities of the species of Pelomonas ranged from 93.3 to $93.5 \%$. The ITS1 sequence similarities between the species of the genera Pelomonas, Roseateles and Mitsuaria and the species of any different genus ranged from 74.3 to $88.8 \%$.

Analysis of the housekeeping gene gyrB (encoding the gyrase $\beta$-subunit) was performed for all strains, amplifying genomic DNA with the forward primer M13Ral-gyrB1F (5' - CAGTCAGGAAACAGCTATGACCGCACAACGGCCGCGGSATTCC-3'), modified from primer gyrB1F of Tayeb et al. (2008), and the reverse primer M13-UgyrBR (5' - CTGATGTAAAACGACGGCCAGTCCGCNGGRTCYTTYTCYTGRCA-3'), modified from primer APrU of Yamamoto et al. (2000). M13 linkers (underlined) were added to the $5^{\prime}$ ends of the PCR primers to generate hybridization sites for sequencing primers on the termini of the amplification products. Primers M13F (5'TCAGGAAACAGCTATGACCGC- $3^{\prime}$ ) and M13R (5'ATGTAAAACGACGGCCAGTCC- $3^{\prime}$ ) and the internal primers Ral-gyrBF422 (5'-TSTCGTTCCTGAACAATGGCG-3') and Ral-gyrBR599 (5'-AGCTGTCGTTCCACTGCATCG-3') were used to determine the primary sequences. The internal primers Ral-gyrBF422 and RalgyrBR599 were designed from the alignment of $\mathrm{gyrB}$ gene sequences in complete genomes as follows: Cupriavidus metallidurans $\mathrm{CH} 34^{\mathrm{T}}$ (GenBank accession no. CP000352), Acidovorax avenae subsp. citrulii AAC00-1 (CP000512), Bordetella pertussis TohamaI (NC_002929), Burkholderia cenocepacia AU1054 (CP000378) and Burkholderia pseudomallei K96243 (NC_006350). Strain KIN192 ${ }^{\mathrm{T}}$ represented a distinct phylogenetic branch related to the Pelomonas species, albeit with a low bootstrap value (less than 500/ 1000 replications) (Supplementary Fig. S3). Four other genes, hox (a hydrogenase), nifH (nitrogenase component), $c b b L$ (ribulose-1,5-bisphosphate carboxylase/oxygenase) and puf (photosynthetic reaction centre component), were analysed as genotypic markers for better definition of the position of the novel strain. However, no amplification products were produced using the PCR primers and conditions described previously for Pelomonas and Roseateles species (Gomila et al., 2007, 2008).

Gas chromatography of fatty acid methyl esters was performed in a standardized protocol, similar to that of the MIDI Sherlock MIS system (http://www.midi-inc. com/; further details at http://www.ccug.se/). Cellular fatty acids were identified and quantified, and the relative amount of each fatty acid was expressed in terms of the percentage of total fatty acids (Table 2). As in other species of related genera, the major cellular fatty acids detected were 
Table 2. Cellular fatty acid compositions of strain $\mathrm{KIN} 192^{\top}$ and type strains of species of closely related genera

Strains: 1, KIN192 ${ }^{\mathrm{T}}$ (K. asaccharophila); 2, P. saccharophila CCUG $32988^{\mathrm{T}}$; 3, P. aquatica CCUG $52575^{\mathrm{T}}$; 4, P. puraquae CCUG $52769^{\mathrm{T}} ; 5$, M. chitosanotabida IAM $14711^{\mathrm{T}} ; 6$, R. depolymerans CCUG $52219^{\mathrm{T}} ; 7$, $R$. terrae CCUG $52222^{\mathrm{T}} ; 8, R$. aquatilis CCUG $48205^{\mathrm{T}}$. Values are percentages of total fatty acids; - , not detected. Abbreviations are exemplified by: 8:0 3-OH, 3-hydroxy-octanoic acid; 12:0, dodecanoic acid; 15:1 $1 \omega 6 c$, cis-9-pentadecenoic acid; $16: 1 \omega 7 c / 15: 0$ iso 2-OH, cis-9-hexadecenoic acid and/or 2-hydroxy-13-methyl-tetradecanoic acid; $18: 2 \omega 6,9 c / 18: 0$ anteiso, cis-9,12-octadecadienoic acid and/ or 15-methyl-heptadecanoic acid; $18: 1 \omega 7 c / 12 t / 9 t$, one or more of cis11-, trans-6- or trans-9-octadecenoic acid.

\begin{tabular}{|c|c|c|c|c|c|c|c|c|}
\hline Fatty acid & 1 & 2 & 3 & 4 & 5 & 6 & 7 & 8 \\
\hline $8: 03-\mathrm{OH}$ & 2.5 & - & - & - & - & - & - & - \\
\hline $10: 03-\mathrm{OH}$ & - & 9.2 & 9.4 & 7.1 & 3.8 & 5.8 & 7.2 & 4.1 \\
\hline $12: 0$ & 2.6 & 7.4 & 7.4 & 4.9 & - & 0.9 & 2.5 & - \\
\hline $12: 02-\mathrm{OH}$ & 1.5 & 3.8 & 1.8 & 2.7 & 2.1 & 2.2 & 1.7 & 2.0 \\
\hline $14: 0$ & 2.0 & 1.3 & 1.8 & 1.0 & 0.8 & 1.2 & 1.7 & 0.5 \\
\hline $15: 1 \omega 6 c$ & 0.4 & - & - & - & - & - & - & - \\
\hline $15: 0$ & 0.8 & 1.0 & 1.4 & 0.6 & 0.2 & 1.3 & - & 0.3 \\
\hline $16: 1 \omega 7 c$ & 45.5 & 41.9 & 43.1 & 47.7 & 44.1 & 42.8 & 45.5 & 44.9 \\
\hline $\begin{array}{l}16: 1 \omega 7 c / 15: 0 \text { iso } \\
2-\mathrm{OH}\end{array}$ & 7.3 & - & - & - & - & - & - & - \\
\hline $16: 0$ & 23.5 & 32.0 & 32.0 & 30.1 & 31.0 & 24.0 & 25.9 & 27.7 \\
\hline $17: 1 \omega 8 c$ & 0.7 & - & - & - & - & - & - & - \\
\hline $17: 1 \omega 6 c$ & 0.5 & - & - & - & - & - & - & - \\
\hline $17: 0$ & 0.6 & - & - & - & - & - & - & - \\
\hline $\begin{array}{l}18: 2 \omega 6,9 c / 18: 0 \\
\text { anteiso }\end{array}$ & 0.3 & - & - & - & - & 0.3 & - & - \\
\hline $18: 1 \omega 9 c$ & 0.4 & - & - & - & - & 0.3 & - & - \\
\hline $18: 1 \omega 7 c / 12 t / 9 t$ & 11.1 & 3.3 & 3.2 & 3.7 & 12.9 & 13.0 & 11.0 & 15.5 \\
\hline $18: 0$ & 0.3 & - & - & 0.5 & 0.5 & 0.4 & - & 0.6 \\
\hline Unidentified & - & - & - & - & - & 0.1 & - & 0.6 \\
\hline
\end{tabular}

cis-9-hexadecenoic $(16: 1 \omega 7 c)$ and hexadecanoic $(16: 0)$ acids. However, distinct differences in the relative proportions of the less-dominant fatty acids were apparent in differentiating KIN $192^{\mathrm{T}}$ from the species of Pelomonas, as well as species of the related genera Mitsuaria and Roseateles. The presence of 3-hydroxy-octanoic acid $(8: 03-\mathrm{OH})$, cis-9pentadecenoic acid $(15: 1 \omega 6 c)$, cis-9-hexadecenoic acid and/or 2-hydroxy-13-methyl-tetradecanoic acid $(16: 1 \omega 7 \mathrm{cl}$ $15: 0$ iso $2-\mathrm{OH})$, cis-9-heptadecenoic acid $(17: 1 \omega 8 c)$, cis-11heptadecenoic acid $(17: 1 \omega 6 c)$ and heptadecanoic acid $(17: 0)$, as well as the absence of 3-hydroxy-decanoic acid (10:0 $3-\mathrm{OH})$, indicated significant differences in overall cellular fatty acid compositions in cells of $\mathrm{KIN} 192^{\mathrm{T}}$ in comparison with species of related genera. The relative amounts of dodecanoic acid (12:0), hexadecanoic acid (16:0) and one or more of cis-11-, trans-6- or trans-9-octadecenoic acid $(18: 1 \omega 7 c / 12 t / 9 t)$ further differentiated strain KIN192 ${ }^{\mathrm{T}}$ chemotaxonomically from Pelomonas species. The relative amounts of 3-hydroxy-octanoic acid and cis-9-hexadecenoic acid and/or 2-hydroxy-13-methyl-tetradecanoic acid, as well as the absence of 3-hydroxy-decanoic acid, allow good discrimination of $\mathrm{KIN} 192^{\mathrm{T}}$ from the species of the genus Pelomonas and the closely related genera Mitsuaria and Roseateles.

Genomic DNA was isolated according to the method of Marmur (1961). DNA-DNA hybridizations were performed in duplicate using a non-radioactive method, as described by Ziemke et al. (1998). DNAs of strain KIN192 ${ }^{\mathrm{T}}$, A. commune CCUG $48318^{\mathrm{T}}$ and P. saccharophila CCUG $32988^{\mathrm{T}}$ were double-labelled with DIG-11-dUTP and biotin-16-dUTP using a nick translation kit (Boehringer Mannheim). Each labelled DNA was hybridized against itself as well as DNAs of the strains $M$. chitosanotabida IAM $14711^{\mathrm{T}}, P$. aquatica CCUG $52575^{\mathrm{T}}$, P. puraquae CCUG $52769^{\mathrm{T}}$, R. aquatilis CCUG $48205^{\mathrm{T}}, R$. depolymerans CCUG $52219^{\mathrm{T}}$ and $R$. terrae CCUG $52222^{\mathrm{T}}$. Genomic DNA-DNA relatedness between $\mathrm{KIN} 192^{\mathrm{T}}$ and the type strains of the species of the genera Pelomonas, Mitsuaria and Roseateles was less than $51 \%$ in all cases when the DNA of strain $\mathrm{KIN} 192^{\mathrm{T}}$ was labelled, and less than $55 \%$ when the DNAs of the complementary strains were labelled, indicating that strain $\mathrm{KIN} 192^{\mathrm{T}}$ could be delineated as representing a novel species in the Rubrivivax branch (Supplementary Table S3).

Determination of $\mathrm{G}+\mathrm{C}$ content was performed for strain $\mathrm{KIN}_{192}{ }^{\mathrm{T}}$ as well as for the type strains of the species of the closest related genera according to Urdiain et al. (2008) (Table 1). The $\mathrm{G}+\mathrm{C}$ content of the genomic DNA of $\mathrm{KIN}_{192}{ }^{\mathrm{T}}$ is $69.3 \mathrm{~mol} \%$.

The Rubrivivax line of descent includes the genera Aquabacterium, Mitsuaria, Roseateles and Pelomonas, constituting an interesting group of micro-organisms for their metabolic capabilities and their relevance in the ecological niches that they occupy. A relevant example is the investigation of the evolution of prokaryotic aerobic phototrophy initiated by Suyama et al. (2002). Unfortunately, the number of strains described for the 10 species of these genera is low, which does not allow good phylogenetic or taxonomic definition. In our opinion, the polyphasic characterization (chemotaxonomic, biochemical and phylogenetic) of more isolates will enable a better understanding and recognition of the species in this phylogenetic branch and, possibly, the unification of the three genera. Strain $\mathrm{KIN} 192^{\mathrm{T}}$ is clearly affiliated phylogenetically to this branch, but does not fit within the spectrum of species described and does not present characteristic phenotypic traits that allow its conclusive adscription to a described genus. Therefore, based on genotypic and phylogenetic analyses, as well as phenotypic and chemotypic characteristics, we conclude that strain KIN192 ${ }^{\mathrm{T}}$ represents a novel genus and species in the Rubrivivax phylogenetic branch, for which the name Kinneretia asaccharophila gen. nov., sp. nov. is proposed.

\section{Description of Kinneretia gen. nov.}

Kinneretia (Kin.ne.re'ti.a. N.L. fem. n. Kinneretia pertaining to Kinneret Lake, where the type strain of the type species was isolated). 
Cells are Gram-negative, rod-shaped (approx. $2 \mu \mathrm{m}$ long) and motile by means of a single polar flagellum. Oxidasepositive and catalase-negative. Not able to assimilate sugars. The major fatty acids are $16: 1 \omega 7 c, 16: 0$ and $18: 1 \omega 7 c / 12 t / 9 t$. Phylogenetically, the genus belongs to the family Comamonadaceae. The type species is Kinneretia asaccharophila.

\section{Description of Kinneretia asaccharophila sp. nov.}

Kinneretia asaccharophila (a.sac.cha.ro'phi.la. Gr. pref. $a-$ not; Gr. n. saccharon sugar; Gr. adj. philos loving; N.L. fem. adj. asaccharophila not sugar loving).

Displays the following properties in addition to those given in the genus description. Colonies are small, approximately $2-3 \mathrm{~mm}$ in width, cream in colour, translucent, with irregular and undulate margins. Good growth occurs in R2A medium between 20 and $37^{\circ} \mathrm{C}$; no growth at 10 or $45{ }^{\circ} \mathrm{C}$. Positive for nitrate reduction. Tryptophanase, glucose fermentation, aesculin hydrolysis, PNPG test and arginine dihydrolase, $\beta$-galactosidase and urease activities are negative, but positive for gelatinase. Negative for growth with D-glucose, L-arabinose, D-mannose, D-mannitol, $\mathrm{N}$-acetylglucosamine, maltose, caprate, L-malate and citrate; good growth with D-gluconate and phenylacetate and extremely weak growth with adipate. Good growth in the presence of $0.5 \% \mathrm{NaCl}$. Positive reactions for alkaline phosphatase, esterase lipase (C8), esterase (C4) and leucyl arylamidase. Negative reactions for lipase (C14), trypsin, chymotrypsin, phosphoamidase, acid phosphatase, $\alpha$-fucosidase, $\alpha$-mannosidase, $N$-acetyl- $\beta$-glucosaminidase, $\alpha$-glucosidase, $\beta$-glucosidase, $\beta$-glucuronidase, $\beta$-galactosidase, $\alpha$-galactosidase and cystine and valine arylamidases. The following compounds are assimilated during growth: acetic acid, D- and L-alanine, L-alaninamide, L-asparagine, 2,3butanediol, $\alpha$-cyclodextrin, dextrin, i-erythritol, L-glutamic acid, glycerol, DL- $\alpha$-glycerol phosphate, glycogen, glycyl L-glutamic acid, $\alpha$-, $\beta$ - and $\gamma$-hydroxybutyric acids, inosine, $\alpha$-ketovaleric acid, DL-lactic acid, L-phenylalanine, pyruvic acid methyl ester, L-proline, hydroxy-L-proline, L-serine, succinic acid monomethyl ester, L-threonine, thymidine, Tweens 40 and 80, uridine and urocanic acid. The following compounds are not assimilated: cis-aconitic acid, adonitol, L-alanyl glycine, $\gamma$-aminobutyric acid, 2-aminoethanol, Larabinose, D-arabitol, L-aspartic acid, glycyl L-aspartic acid, bromosuccinic acid, DL-carnitine, cellobiose, citric acid, formic acid, D-fructose, L-fucose, D-galactonic acid lactone, $\mathrm{N}$-acetyl-D-galactosamine, D-galactose, D-galacturonic acid, gentiobiose, D-gluconic acid, $N$-acetyl-D-glucosamine, Dglucosaminic acid, $\alpha$-D-glucose, $\alpha$-D-glucose 1 -phosphate, D-glucose 6-phosphate, methyl $\beta$-D-glucoside, glucuronamide, D-glucuronic acid, L-histidine, myo-inositol, itaconic acid, $\alpha$-ketobutyric acid, $\alpha$-ketoglutaric acid, $\alpha$-lactose, lactulose, L-leucine, malonic acid, maltose, D-mannitol, Dmannose, melibiose, L-ornithine, $p$-hydroxyphenylacetic acid, phenylethylamine, propionic acid, D-psicose, putrescine, L-pyroglutamic acid, quinic acid, raffinose, L-rham- nose, D-saccharic acid, sebacic acid, D-serine, D-sorbitol, succinamic acid, succinic acid, sucrose, trehalose, turanose and xylitol. The $\mathrm{G}+\mathrm{C}$ content of the genomic DNA of the type strain is $69.3 \mathrm{~mol} \%$.

The type strain, $\mathrm{KIN} 192^{\mathrm{T}} \quad\left(=\mathrm{CCUG} 53117^{\mathrm{T}}=\mathrm{CECT}\right.$ $7319^{\mathrm{T}}$ ), was isolated from fresh water of Lake Kinneret, Israel.

\section{Acknowledgements}

This work was supported by FEDER funding and CICYT (Spain) grant CGL2006-09719/BOS and by the 'Plà Balear de Recerca I Desenvolupament Tecnològic de les Illes Balears'. M. G. was the recipient of a mobility fellowship from the Spanish Ministerio de Educación y Ciencia, by means of the José Castillejo Program. The isolation of KIN $192^{\mathrm{T}}$ was possible thanks to a grant from the Swedish Royal Academy of Sciences to J.P. We gratefully acknowledge the help of Ramon Rosselló-Mora and Mercedes Urdiain with G+C content measurement and constructive discussions. The technical assistance of Kent Molin (CCUG) with the cellular fatty acid (FAME) determination and Brian Tindall (DSMZ) for his advice on the cellular fatty acid analyses are also acknowledged. We also thank Tetsushi Suyama for helpful discussions and his generous gift of strains, thus enabling these studies.

\section{References}

Altschul, S. F., Gish, W., Miller, W., Myers, E. W. \& Lipman, D. J. (1990). Basic local alignment search tool. J Mol Biol 215, 403-410.

Amakata, D., Matsuo, Y., Shimono, K., Park, J. K., Yun, C. S., Matsuda, H., Yokota, A. \& Kawamukai, M. (2005). Mitsuaria chitosanotabida gen. nov., sp. nov., an aerobic, chitosanase-producing member of the 'Betaproteobacteria'. Int J Syst Evol Microbiol 55, 19271932.

Cowan, S. T. (1974). Cowan and Steel's Manual for the Identification of Medical Bacteria, 2nd edn. London: Cambridge University Press.

Felsenstein, J. (1989). PHYLIP - phylogeny inference package (version 3.0). Cladistics 5, 164-166.

Gomila, M., Gascó, J., Busquets, A., Gil, J., Bernabeu, R., Buades, J. M. \& Lalucat, J. (2005). Identification of culturable bacteria present in haemodialysis water and fluid. FEMS Microbiol Ecol 52, 101-114.

Gomila, M., Bowien, B., Falsen, E., Moore, E. R. B. \& Lalucat, J. (2007). Description of Pelomonas aquatica sp. nov. and Pelomonas puraquae sp. nov., isolated from industrial and haemodialysis water. Int J Syst Evol Microbiol 57, 2629-2635.

Gomila, M., Bowien, B., Falsen, E., Moore, E. R. B. \& Lalucat, J. (2008). Description of Roseateles aquatilis sp. nov. and Roseateles terrae sp. nov., in the class Betaproteobacteria, and emended description of the genus Roseateles. Int J Syst Evol Microbiol 58, 611.

Guasp, C., Moore, E. R. B., Lalucat, J. \& Bennasar, A. (2000). Utility of internally transcribed 16S-23S rDNA spacer regions for the definition of Pseudomonas stutzeri genomovars and other Pseudomonas species. Int J Syst Evol Microbiol 50, 1629-1639.

Jukes, T. H. \& Cantor, C. R. (1969). Evolution of protein molecules. In Mammalian Protein Metabolism, vol. 3, pp. 21-132. Edited by H. N. Munro. New York: Academic Press.

Kalmbach, S., Manz, W., Wecke, J. \& Szewzyk, U. (1999). Aquabacterium gen. nov., with description of Aquabacterium citratiphilum sp. nov., Aquabacterium parvum sp. nov. and Aquabacterium 
commune sp. nov., three in situ dominant bacterial species from the Berlin drinking water system. Int J Syst Bacteriol 49, 769-777.

Lalucat, J. (1988). Analysis of refractile (R) bodies. Methods Microbiol 20, 79-90.

Marmur, J. (1961). A procedure for the isolation of DNA from microorganisms. J Mol Biol 3, 208-218.

Page, R. D. M. (1996). TreeView: an application to display phylogenetic trees on personal computers. Comput Appl Biosci 12, 357-358.

Pinhassi, J. \& Berman, T. (2003). Differential growth response of colony-forming $\alpha$ - and $\gamma$-proteobacteria in dilution culture and nutrient addition experiments from Lake Kinneret (Israel), the eastern Mediterranean Sea, and the Gulf of Eilat. Appl Environ Microbiol 69, 199-211.

Reasoner, D. J. \& Geldreich, E. E. (1985). A new medium for the enumeration and subculture of bacteria from potable water. Appl Environ Microbiol 49, 1-7.

Spring, S. (2006). The genera Leptothrix and Sphaerotilus. In The Prokaryotes: a Handbook on the Biology of Bacteria, 3rd edn, vol. 5, pp. 758-777. Edited by M. Dworkin, S. Falkow, E. Rosenberg, K. H. Schleifer \& E. Stackebrandt. New York: Springer.

Suyama, T., Tokiwa, Y., Ouichanpagdee, P., Kanagawa, T. \& Kamagata, Y. (1998). Phylogenetic affiliation of soil bacteria that degrade aliphatic polyesters available commercially as biodegradable plastics. Appl Environ Microbiol 64, 5008-5011.

Suyama, T., Shigematsu, T., Takaichi, S., Nodasaka, Y., Fujikawa, S., Hosoya, H., Tokiwa, Y., Kanagawa, T. \& Hanada, S. (1999). Roseateles depolymerans gen. nov., sp. nov., a new bacteriochlorophyll $a$-containing obligate aerobe belonging to the $\beta$-subclass of the Proteobacteria. Int J Syst Bacteriol 49, 449-457.
Suyama, T., Shigematsu, T., Suzuki, T., Tokiwa, Y., Kanagawa, T., Nagashima, K. V. P. \& Hanada, S. (2002). Photosynthetic apparatus in Roseateles depolymerans $61 \mathrm{~A}$ is transcriptionally induced by carbon limitation. Appl Environ Microbiol 68, 1665-1673.

Tayeb, L. A., Lefevre, M., Passet, V., Diancourt, L., Brisse, S. \& Grimont, P. A. (2008). Comparative phylogenies of Burkholderia, Ralstonia, Comamonas, Brevundimonas and related organisms derived from $r p o B, g y r B$ and $r r s$ gene sequences. Res Microbiol 159, 169-177.

Thompson, J. D., Gibson, T. J., Plewniak, F., Jeanmougin, F. \& Higgins, D. G. (1997). The CLUSTAL_X windows interface: flexible strategies for multiple sequence alignment aided by quality analysis tools. Nucleic Acids Res 25, 4876-4882.

Urdiain, M., López-López, A., Gonzalo, C., Busse, H. J., Langer, S., Kämpfer, P. \& Rosselló-Móra, R. (2008). Reclassification of Rhodobium marinum and Rhodobium pfennigii as Afifella marina gen. nov. comb. nov. and Afifella pfennigii comb. nov., a new genus of photoheterotrophic Alphaproteobacteria and emended descriptions of Rhodobium, Rhodobium orientis and Rhodobium gokarnense. Syst Appl Microbiol 31, 339-351.

Xie, C.-H. \& Yokota, A. (2005). Reclassification of Alcaligenes latus strains IAM $12599^{\mathrm{T}}$ and IAM 12664 and Pseudomonas saccharophila as Azohydromonas lata gen. nov., comb. nov., Azohydromonas australica sp. nov. and Pelomonas saccharophila gen. nov., comb. nov., respectively. Int J Syst Evol Microbiol 55, 2419-2425.

Yamamoto, S., Kasai, H., Arnold, D. L., Jackson, R. W., Vivian, A. \& Harayama, S. (2000). Phylogeny of the genus Pseudomonas: intrageneric structure reconstructed from the nucleotide sequences of gyrB and rpoD genes. Microbiology 146, 2385-2394.

Ziemke, F., Höfle, M. G., Lalucat, J. \& Rosselló-Mora, R. (1998). Reclassification of Shewanella putrefaciens Owen's genomic group II as Shewanella baltica sp. nov. Int J Syst Bacteriol 48, 179-186. 